\title{
Desenvolvimento de hambúrguer vegano adicionado da farinha de couve folha: avaliação físico-química, microbiológica e sensorial
}

\author{
Development of vegan hamburger added from leaf cabbage flour: physical-chemical, \\ microbiological and sensory evaluation
}

Desarrollo de hamburguesa vegana añadida a partir de harina de repollo de hoja: evaluación físico-química, microbiológica y sensorial

\author{
Jair Francisco de Lima Segundo \\ ORCID: https://orcid.org/0000-0002-8683-6065 \\ Universidade Federal de Campina Grande, Brasil \\ E-mail: jairlimasegundo@gmail.com \\ Heloísa Maria Ângelo Jerônimo \\ ORCID: https://orcid.org/0000-0002-3139-4589 \\ Universidade Federal de Campina Grande, Brasil \\ E-mail: helogero@yahoo.com.br \\ Vanessa Bordin Viera \\ ORCID: https://orcid.org/0000-0003-4979-4510 \\ Universidade Federal de Campina Grande, Brasil \\ E-mail: vanessa.bordinviera@gmail.com \\ Camila Maria Sousa de Andrade Nascimento \\ ORCID: https://orcid.org/0000-0003-4380-1433 \\ Universidade Federal de Campina Grande, Brasil \\ E-mail: camilanutriufcg@gmail.com
}

\begin{abstract}
Resumo
Em constante ascensão, o número de pessoas adeptas ao veganismo impõe ao mercado alternativas alimentares diversificadas, sendo assim, é de grande relevância o desenvolvimento de alimentos com formulações que visem a substituição da matéria cárnea animal pela de origem vegetal. Desta forma, a utilização da jaca como base para elaboração de um hambúrguer pode mostrar-se como potencial alimentício e socioeconômico. Objetivou-se elaborar e realizar análises físico-química, microbiológica, sensorial e de rendimento em hambúrgueres de "carne de jaca" adicionados de um mix de farinhas da semente do fruto e da couve folha. Foram selecionadas jacas, da variedade "dura", imaturas. Após a higienização e sanitização, uma parte das frutas foi tratada termicamente ao forno para posterior separação da polpa e semente, que foi congelada e transformada em farinha, respectivamente, assim como na porção in natura. Em seguida, após elaboração, as duas formulações de hambúrguer foram submetidas às análises supracitadas, sendo que na avaliação sensorial as amostras foram submetidas a processo térmico e assim 60 provadores realizaram teste de aceitação em escala hedônica de 9 pontos e de intenção de compra. Ao final da pesquisa, o produto não apresentou diferenças físico-quimicas, mostrou boas características microbiológicas e obteve boas aceitação sensorial para a amostra HV01, demostrando potencial em ser uma boa colaboração com a indústria alimentícia, oferecendo assim uma mais opção mercadológica para o número crescente de indivíduos veganos.
\end{abstract}

Palavras-chave: Análise de alimentos; Carne vegetal; Indústria alimentícia.

\begin{abstract}
In a constant rise, the number of people adept at veganism imposes on the market diversified food alternatives, therefore, it is of great importance the development of foods with formulations that aim at the substitution of animal meat material by plant origin. Thus, the use of jackfruit as a basis for making a hamburger can be shown as a nutritional and socioeconomic potential. The objective was to elaborate and carry out physical-chemical, microbiological, sensory and performance analyzes on "jackfruit" hamburgers added with a mix of flours from the seed of the fruit and the cabbage leaf. Immature jackfruits of the "hard" variety were selected. After cleaning and sanitizing, part of the fruit was heat treated in the oven for subsequent separation of the pulp and seed, which was frozen and transformed into flour, respectively, as well as in the fresh portion. Then, after elaboration, the two hamburger formulations were subjected to the aforementioned analyzes, and in the sensory evaluation the samples were subjected to a thermal process and thus 60 tasters performed acceptance test on a 9-point hedonic scale and purchase intention. At the end of the research, the product showed no physical-chemical differences, showed good microbiological characteristics and obtained good sensory
\end{abstract}


acceptance for the HV01 sample, showing the potential to be a good collaboration with the food industry, thus offering a more marketing option for the growing number of vegan individuals.

Keywords: Food analysis; Vegetable meat; Food industry.

\section{Resumen}

En constante aumento, el número de personas expertas en veganismo impone al mercado alternativas alimentarias diversificadas, por lo que es de gran importancia el desarrollo de alimentos con formulaciones destinadas a reemplazar la materia cárnica animal por las de origen vegetal. Por lo tanto, el uso de la fruta de gato como base para la preparación de una hamburguesa se puede mostrar como alimento y potencial socioeconómico. El objetivo de este estudio fue elaborar y realizar análisis físico-químicos, microbiológicos, sensoriales y de rendimiento en hamburguesas "de carne de res" añadidas a partir de una mezcla de harina de semilla de fruta y hoja de repollo. Jacas de la variedad "dura", inmaduro fueron seleccionados. Después de la desinfección y desinfección, parte de los frutos fueron tratados térmicamente en el horno para la posterior separación de la pulpa y la semilla, que se congeló y transformó en harina, respectivamente, así como en la porción in natura. Luego, después de la elaboración, las dos formulaciones de hamburguesas fueron sometidas a los análisis antes mencionados, y en la evaluación sensorial las muestras fueron sometidas a proceso térmico y así 60 catadores realizaron pruebas de aceptación a escala hedónica de 9 puntos e intención de compra. Al final de la investigación, el producto no presentaba diferencias físico-químicas, mostraba buenas características microbiológicas y obtenía una buena aceptación sensorial para la muestra HV01, mostrando potencial para ser una buena colaboración con la industria alimentaria, ofreciendo así una opción más de mercado para el creciente número de individuos veganos.

Palabras clave: Análisis de alimentos; Carne de verduras; Industria alimentaria.

\section{Introdução}

No decorrer de séculos, as dietas vegetarianas/veganas foram empregadas para complementar as necessidades nutricionais, muitas vezes devido às carências financeiras nos países subdesenvolvidos. No entanto, a sua prática foi relacionada a questões éticas e religiosas, e correlacionada a uma noção de padrão saudável no estado nutricional dos indivíduos. Pitágoras é considerado o fundador do movimento vegetariano, pois ele acreditava em reencarnação, o que o levou a se abster de consumir animais, porém o mais antigo manuscrito sobre exclusão de produtos cárneos data do século 6 a.c. na Europa quando um grupo religioso que fundou o Orfismo, uma crença religiosa de origem Grega que tinha como regra o consumo alimentar interdito de carne, pois a alma poderia reencarnar em animais, banindo assim o sacrifício dos mesmos. Algumas religiões, tais como o Budismo e o Hinduísmo, promovem o uso de dietas vegetarianas/veganas com o intuito de preservar a vida animal (Pedro, 2010).

$\mathrm{Na}$ atualidade, o fundamento religioso para explicar tais práticas alimentares deixa de ter grande evidência para dar lugar a ressignificação da relação entre humanos e animais, elevando assim a ideia de que esses seres vivos não seriam completamente irracionais, uma vez que, a senciência observada nestes seria então critério de pertencimento à comunidade moral e racional, ou seja , a capacidade de sentir sensações e sentimentos de forma consciente tornam-nos dignos de um maior respeito e importância, caracterizando assim o movimento vegano (Trigueiro, 2013).

A principal atenção no âmbito da nutrição se dá pelo fato de que a exclusão dos alimentos de origem animal na dieta possa causar um déficit no aporte proteico relacionado aos aminoácidos essenciais. Outro ponto de grande atenção é em relação aos micronutrientes, em especial as vitaminas B12 e D e os minerais cálcio, ferro e zinco, fato de se encontrarem, sobretudo mais biodisponíveis em alimentos de origem animal (Karlsen et al.,2019).

Levando em consideração os aspectos religiosos, éticos e principalmente os relacionados a saúde, é de grande importância que a indústria busque investir cada vez mais na elaboração de produtos alimentícios que proporcionem uma variabilidade de gêneros disponíveis para a população vegetariana/vegana. Além disso, a busca por matéria prima para processamento dos mesmos deve dar importância a insumos que proporcionem o aporte nutricional adequado baseado nas carências nutricionais já citados anteriormente. Sendo assim, questiona-se se um produto elaborado integralmente a partir de uma fruta subutilizada adicionado de uma hortaliça teria viabilidade no mercado consumidor.

Tendo em vista a preocupação com o grupo de indivíduos em questão, sobre alternativas alimentares disponíveis no mercado, é de grande relevância o desenvolvimento de um produto com formulação que vise à modificação da matéria cárnea 
pela de origem vegetal e, assim, destiná-lo ao mercado de veganos e consumidores em geral. Vários estudos demonstram a eficácia da elaboração de produtos, que sempre foram formulados com matéria prima animal, a partir de bases vegetais. É o que comprova a pesquisa feita por Lima (2018) sobre o desenvolvimento de um produto alimentar vegetal que atuasse como fonte proteica da dieta em substituição à proteína animal utilizando grão-de-bico e resíduo agroindustrial de acerola. Assim sendo, seria uma alternativa viável a produção de um hambúrguer elaborado com a base vegetal polpa de jaca dura (Artocarpus heterophyllus) enriquecido com um mix de farinhas de semente da jaca e couve folha, haja vista que, um estudo feito por Morais et al. (2016), utilizando o fruto e a farinha da semente da jaca dura, resultou em uma escolha para a elaboração de hambúrguer vegetariano, visto que, os aspectos tecnológicos como, textura, coesão e firmeza alcançaram resultados positivos.

Dessa forma, a pesquisa em pauta proporcionará consideráveis benefícios, dado que, a elaboração de um gênero voltado à população que na contemporaneidade ainda sofre com a escassez de opções disponíveis no mercado alimentício, implicará em uma crescente percepção social sobre esse estilo de vida, que não leva em consideração apenas o alimentar-se, mas também o respeito com a vida animal. A matéria-prima definida para essa pesquisa buscou dar perceptibilidade a um fruto que muitas vezes é perdido em razão da sua rápida maturação, tendo suas sementes e polpas rapidamente decompostas pela natureza, tendo o mesmo um bom valor nutricional, tornando bastante interessante a ideia de criar diversificadas estratégias para seu beneficiamento, a fim de aproveitar a abundante fonte nutricional e alimentar que a mesma significa.

\section{Metodologia}

O estudo propôs, do ponto de vista da sua natureza, de uma pesquisa aplicada que determina a geração de discernimento sobre os ascendentes adeptos ao estilo de vida em questão, além de esclarecer a população sobre o tema, e teve como propósito corroborar com a indústria alimentícia, a partir da elaboração de um novo gênero alimentício vegano, que consequentemente será capaz de oportunizar, em relação às escolhas alimentares, a autonomia desses indivíduos no mercado local e nacional.

Em referência aos seus objetivos, a pesquisa em questão teve caráter descritivo por meio do registro e detalhamento dos resultados obtidos mediante a realização das análises. A caracterização desse estudo envolveu o uso de recursos humanos, por meio da aplicação de um formulário de teste de aceitação e intenção de compra. As demais empregaram apenas meios tecnológicos como testes microbiológicos e bromatológicos.

Do ponto de vista dos procedimentos técnicos a pesquisa possuiu natureza experimental. Após a determinação objeto das amostras, duas variantes foram escolhidas para definir qual demonstraria melhores resultados, para que assim possa observar os efeitos que as variáveis influíram no produto final. Já sobre a abordagem do tema, a pesquisa foi quantitativa, onde no decorrer do desenvolvimento da mesma foram elaboradas possibilidades no intuito de categorizar a associação entre as variáveis para assegurar a exatidão dos resultados, averiguando discriminações no processo de análise e interpretação (Pereira et al. 2018).

A pesquisa foi realizada no bloco "J" das dependências do CES - Centro de Educação e Saúde da UFCG - Universidade Federal de Campina Grande - campus Cuité/PB. Os processamentos da matéria prima foram realizados nas dependências do LABROM, onde também foram efetuadas as análises físico-químicas, e no LASA, local onde foram formuladas as amostras e chapeadas para a aplicação dos testes de aceitabilidade e intenção de compra. As análises microbiológicas foram feitas no LABMA. Os laboratórios acima citados dispõem de todos os equipamentos e estruturas para a realização do processamento e respectivas análises.

\subsection{Obtenção da base vegetal}

As jacas do tipo dura foram adquiridas na zona rural da cidade de Cuité/PB, mais precisamente na comunidade Lagoa do Meio. Deu-se preferência os frutos imaturos (verdes) e o estágio de maturação foi determinado através da consistência dura 
do fruto. Para a obtenção das amostras para análise, os frutos foram colocados em molho e higienizados em solução aquosa de hipoclorito de sódio 2,5\% e posteriormente lavados com água corrente para retirada do excesso de hipoclorito.

Os frutos imaturos foram processados de duas formas, uma parte processada in natura e outra foi tratada termicamente por cocção seca. Na amostra tratada termicamente os frutos foram dispostos em formas de alumínio e cobertos com papel laminado, deixando-os em forno doméstico por 1 hora a $220^{\circ} \mathrm{C}$. Posteriormente foram processados para a separação da polpa, mesocarpo e sementes, assim como na amostra in natura. As sementes, após serem higienizadas em água corrente foram manuseadas de forma a retirar os resquícios orgânicos da polpa. Após a lavagem, foram secas em papel toalha. A polpa tratada termicamente, a crua e as sementes foram armazenadas em diferentes sacos plásticos transparentes, identificadas e congeladas em frezzer frostfree (Electrolux RF46-220W) em temperatura entre $-15^{\circ} \mathrm{C} \mathrm{e}-18^{\circ} \mathrm{C}$ até seu processamento e análises.

\subsection{Obtenção da farinha da semente de jaca}

Para a obtenção da farinha, os frutos de jaca foram processados de acordo com fluxograma apresentado na Figura 1. Utilizou-se sementes de jaca dura imatura congeladas (processamento descrito anteriormente) que foram lavadas em água corrente para remoção dos resíduos de polpa e então imersas em solução aquosa de hipoclorito de sódio 2,5\%. Para a redução de umidade, as sementes foram secas em estufa a $75^{\circ} \mathrm{C}$ por 2 horas (BIOPAR, Modelo 8480 AD) e, depois de secas, trituradas em um liquidificador doméstico. A farinha obtida foi, então, seca em estufa $\left(80^{\circ} \mathrm{C}\right.$ por 2 horas $)$, moída para a padronização da granulometria por peneiramento e armazenada em saco de polietileno, selados e etiquetados para serem armazenados à temperatura de $-10^{\circ} \mathrm{C}$ até a posterior utilização na fabricação dos hambúrgueres.

Figura 1 - Fluxograma de obtenção da farinha da semente de jaca.

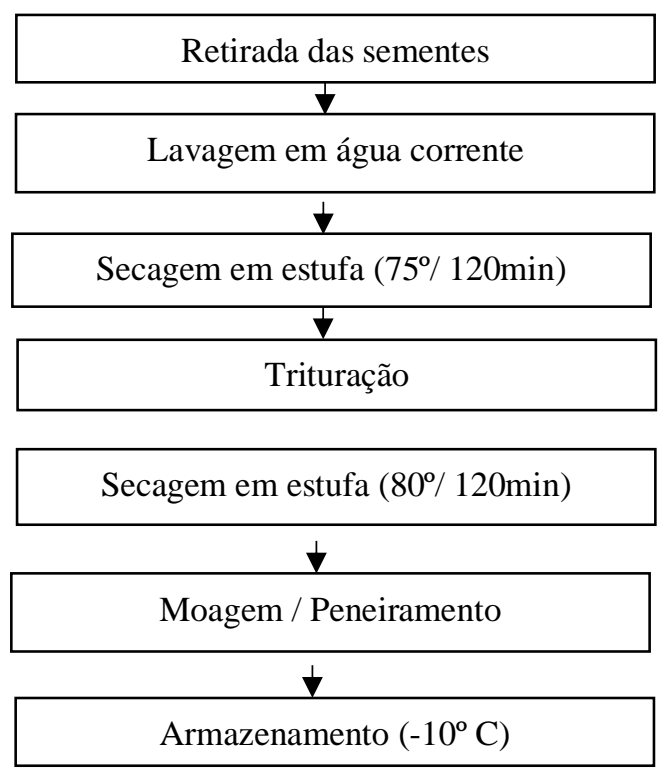

Fonte: Adaptado de Landim (2012).

\subsection{Obtenção da farinha da couve-folha}

A farinha foi obtida a partir das folhas de couve manteiga (Brassicaoleracea, L.), as quais, anteriormente, foram higienizadas em água corrente e sanitizadas com hipoclorito de sódio a 2,5\% por 15 minutos. Após essa etapa, as amostras foram cortadas em pequenos pedaços, branqueadas (em água fervente por 3 minutos), para desnaturar enzimas associadas ao processo de deterioração, e escorridas. A secagem (desidratação) das folhas foi realizada em estufa ventilada a $50{ }^{\circ} \mathrm{C}$ por 24 horas. Para 
a obtenção da farinha, depois de desidratados, os talos foram submetidos a trituração em liquidificador doméstico, acondicionados em sacos de polietileno, selados e etiquetados, e estocados em freezer a $-10{ }^{\circ} \mathrm{C}$.

\subsection{Formulação dos hambúrgueres}

Para o processamento dos hambúrgueres, optou-se pela utilização dos frutos imaturos e suas respectivas frações, in natura e tratadas termicamente. A polpa e o mesocarpo da jaca tratados para as duas formulações passaram por um tratamento em solução aquosa de ácido acético 5\% e lavada com água potável. Após as lavagens, a água foi retirada e as matérias-primas foram homogeneizadas para a formação da base vegetal sendo trituradas em processador (Philips/Walita RI7625-500W) por 10 minutos.

Foram desenvolvidas duas formulações de hambúrguer vegano. Os ingredientes utilizados nas formulações estão apresentados na Tabela 1. Foram atribuídos códigos para cada formulação, sendo eles: HV01 - jaca in natura; HV02 - jaca tratada termicamente. Ambas formulações receberam a mesma concentração de condimentos, farinha da semente e da couve folha. O conteúdo final do processamento das amostras foi dividido em partes para serem utilizadas nas a análises físico-química, microbiológica, sensorial e de rendimento.

Tabela 1 - Ingredientes para a formulação dos hambúrgueres.

\begin{tabular}{lcc}
\hline Ingredientes & \multicolumn{2}{c}{ Formulações } \\
\cline { 2 - 3 } & HV01 & HV02 \\
\hline Polpa de jaca-dura & $55 \%$ & $55 \%$ \\
Farinha da semente de jaca & $15 \%$ & $15 \%$ \\
Farinha de couve-folha & $8 \%$ & $8 \%$ \\
Fécula de mandioca & $15 \%$ & $15 \%$ \\
Cebola em pó & $1,5 \%$ & $1,5 \%$ \\
Alho em pó & $2 \%$ & $2 \%$ \\
Orégano & $1,5 \%$ & $1,5 \%$ \\
Sal & $1 \%$ & $1 \%$ \\
Fumaça em pó & $1 \%$ & $1 \%$ \\
\hline
\end{tabular}

HV01 - jaca in natura; HV02 - jaca tratada termicamente. Fonte: Adaptado de Paula et al. (2019).

A escolha dos ingredientes deu-se a partir de estudos preliminares que demonstraram que formulações apenas com farinha da semente de jaca expressaram menor adesão aos componentes da base vegetal em função da alta granulometria, o que resultou em um produto com baixa aglutinação, friável e com maior percepção farinácea. Com adição da farinha de jaca e de fécula de mandioca percebe-se permutabilidade na granulometria, atribuindo ao produto mais resistência em sua textura e menor umidificação (Morais et al. 2016).

A preferência por condimentos em pó ocorreu de forma experimental, visto que, os vegetais de forma integral não se ligaram de forma efetiva na base vegetal, dificultando assim a agregação de sabor especifico ao hambúrguer, o que posteriormente resultaria em um produto não palatável e de baixa aceitabilidade.

O fluxograma do preparo da matéria-prima e a sequência de e análises realizadas no "Hambúrguer vegano" adicionado de farinha de couve-folha pode ser observado a seguir, na Figura 2. 
Figura 2 - Fluxograma do preparo do "Hambúrguer vegano".

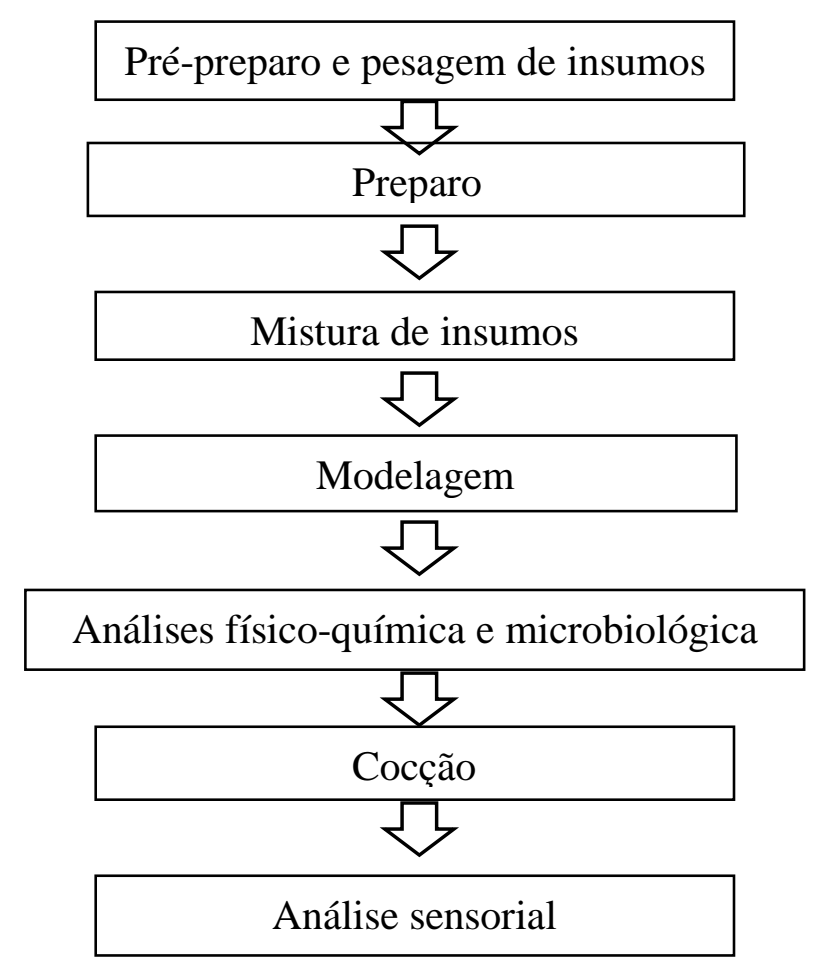

Fonte: Adaptado de Paula et al. (2019).

\subsection{Análises físico-químicas do produto antes da cocção}

Utilizou-se as metodologias do Instituto Adolfo Lutz (2008) quanto aos parâmetros atividade de água, que foi definido pela leitura de 1 grama de amostra em Aqualab. A acidez titulável foi estipulada titulando-se a amostra com solução de hidróxido de sódio $0,1 \mathrm{~mol} / \mathrm{L}$ e utilizando-se fenolftaleína como indicador, o resultado final foi expresso em percentagem de ácido cítrico. Já para análise dos outros parâmetros a metodologia utilizada foi a do AOAC International (1995) onde a umidade foi determinada pelo método de secagem das amostras até peso constante, em estufa a $105^{\circ} \mathrm{C}$ durante 24 horas. As cinzas foram determinadas após completa carbonização em incineração das amostras em mufla a $550^{\circ} \mathrm{C}$, até a obtenção de um resíduo isento de carvão, com coloração branca acinzentada. Os lipídeos foram determinados pelo método de Folch (1957).

Após a modelagem, as análises realizadas, no que se refere a físico-química e microbiológica, foram realizadas nas amostras em triplicata nas duas formulações, in natura e tratada termicamente, da jaca dura imatura.

\subsection{Análise microbiológica}

A avaliação da qualidade microbiológica das amostras, investigou a presença de bolores e leveduras e coliformes, conforme o a Instrução Normativa $\mathrm{n}^{\circ}$ 60, de 23 de Dezembro de 2019; $\mathrm{n}^{\circ}$ 2; Item "c", que define critérios e padrões microbiológicos para preparados (inteiros, descascados ou fracionados), sanificados, branqueados, pré-fritos, refrigerados ou congelados, que necessitam de tratamento térmico efetivo previamente ao consumo (Brasil, 2019).

\subsection{Análise sensorial}

Para o teste de aceitação utilizou-se escala hedônica não estruturada, em nove pontos, empregando-a para obter os seguintes parâmetros: aparência (aspecto exterior), cor (avaliação visual da coloração da amostra), sabor (sensação de gosto e odor liberados pela amostra durante a mastigação), consistência (percepção da força necessária para o cisalhamento da amostra por meio da mordida) e avaliação global (somatório de todas as percepções sensoriais expressando o exame dos julgadores sobre 
a qualidade do produto). Os nove pontos da escala consistiram em: 1 - desgostei muitíssimo; 2 - desgostei muito; 3 - desgostei moderadamente; 4 - desgostei ligeiramente; 5 - nem gostei/nem desgostei; 6 - gostei ligeiramente; 7 - gostei moderadamente; 8 - gostei muito; e 9 - gostei muitíssimo. Para a avaliação da intenção de compra, foram elencados cinco pontos, 5 - compraria; 4 -possivelmente compraria, 3 - talvez comprasse/ talvez não comprasse, 2 -possivelmente não compraria, 1 - jamais compraria.

\subsection{Análise do rendimento}

As amostras foram pesadas após o processamento e aferidos seus diâmetros, em triplicata, antes e após tratamento térmico. Conforme equação 01 para porcentagem de rendimento e equação 02 para porcentagem de encolhimento (Mansour \& Khalil, 1997).

Equação 01: \% rendimento $=\underline{\text { Peso da amostra cozida }} \times 100$

Peso da amostra crua

Equação 02: \% encolhimento $=\underline{(\text { Diâmetro da amostra crua }- \text { Diâmetro da cozida })} \times 100$

Diâmetro da amostra crua

\subsection{Análise estatística}

Apenas para interpretação dos dados da análise sensorial, por teste de diferença, utilizou-se os softwares Excel e SigmaStat 3.5, utilizando-se as médias que foram comparadas pelo teste t de Tukey e o teste de t Student ao nível de 5\% de significância.

\subsection{Aspectos éticos}

Por se tratar de uma pesquisa com seres humanos, a análise sensorial exigiu o termo de consentimento livre e esclarecido conforme modelo, incluído no Apêndice A. Como critérios de exclusão, não puderam fazer parte desta pesquisa os participantes alérgicos a jaca, à couve folha ou algum dos componentes. Apresentaram-se mínimos os riscos e desconfortos para os participantes que não se enquadraram em nenhum dos critérios de exclusão e se dispuserem voluntariamente a participar do teste. $\mathrm{O}$ benefício aos participantes que experimentaram o hambúrguer vegano, foi perceber que existem insumos unicamente vegetais para produzir hambúrguer, sem perder a qualidade nutricional e sensorial. Os dados obtidos na pesquisa são extremamente confidenciais e somente serão utilizados para estudo, para a divulgação dos resultados, não sendo necessário divulgar nenhum dado pessoal dos participantes, mostrando a confidencialidade da pesquisa. A pesquisa foi aprovada pelo CEP/HUAC, sob o número 3.784.633.

\section{Resultados}

\subsection{Caracterização físico-química}

De acordo com a Tabela 2, podemos observar as características físico-químicas das duas amostras do "hambúrguer tipo vegano". Observa-se em relação aos valores de umidade para a amostra formulada com a jaca dura in natura HV01 (57,23\%) se mostrou relativamente aumentada em relação a amostra tratada termicamente HV02 (54,68\%), mesmo que a diferença não seja expressivamente significante $(\mathrm{p}=0,1)$, a redução desse parâmetro no produto pode ter ocorrido em razão do processamento térmico. 
Tabela 2 - Parâmetros físico-químicos dos hambúrgueres.

\begin{tabular}{lcc}
\hline & \multicolumn{2}{c}{ Formulações } \\
\cline { 2 - 3 } Análises & HV01 & HV02 \\
\hline Umidades (\%) & $57,23 \pm 0,19$ & $54,68 \pm 0,44$ \\
$A w$ & $0,991 \pm 0,002$ & $0,978 \pm 0,002$ \\
Cinzas $(\%)$ & $2,56 \pm 0,02$ & $2,58 \pm 0,01$ \\
Acidez (\%) & $0,48 \pm 0,07$ & $0,45 \pm 0,05$ \\
Lipídeos (\%) & $2,15 \pm 0,099$ & $1,00 \pm 0,001$ \\
\hline
\end{tabular}

Resultados das análises físico-químicas das amostras HV01 - jaca in natura; HV02 - jaca tratada termicamente. Os dados foram analisados utilizando médias comparadas pelo teste t-test ao nível de 5\% de significância. Fonte: Autores.

Em relação à atividade de água não foram observadas diferenças significativas nas amostras analisadas $(\mathrm{p}=0,1)$. Os valores observados do HV01 $(0,991)$ e do HV02 $(0,978)$ são bem altos, expondo assim a suculência que esse fruto apresenta. Coincidentemente, os resultados encontrados para cinzas nas duas amostras também não expuseram distinções consideráveis ( $\mathrm{p}=0,336)$, para o HV01 (2,56\%) e HV02 (2,58\%). Então, pode-se pressupor que a mistura de insumos na preparação das duas amostras e o processo térmico na amostra HV02 não alteraram estatisticamente a atividade de água e seu conteúdo em minerais.

Um dos métodos empregados frequentemente para medir a acidez de frutos é a percentagem de ácido orgânico, sendo assim, realizou-se análises de acidez titulável nas duas amostras de hambúrguer. De acordo com os resultados encontrados podese observar valores reduzidos para HV01 $(0,48 \%)$ e HV02 $(0,45 \%)$, no qual as mesmas não diferiram significativamente ( $\mathrm{p}=0,333)$, sugerindo assim que o processamento não influenciou a acidez dos hambúrgueres.

Com relação ao teor de lipídeos, pode-se observar que o processamento do (HV01) resultou em um produto com $(2,15 \%)$, moderadamente elevado com relação a amostra tratada termicamente (HV02) que apresentou (1,00\%) no total de lipídeos. Os valores médios entre as formulações $(\mathrm{p}=0,333)$ não diferiram estatisticamente podendo-se dizer que o processamento térmico não interferiu no teor de lipídeos do hambúrguer elaborado.

\subsection{Caracterização microbiológica}

De maneira que este se trata de um produto não disponível no mercado, não existem padrões microbiológicos para confrontação dos resultados, restando assim compara-los com produtos semelhantes para identificação de não conformidade em função da atividade microbiológica. Para verificar as condições microbiológicas destas obtiveram-se os resultados como mostra a Tabela 04, (ver Tabela 3). Contudo, os resultados obtidos foram comparados com produtos em que seu processamento se assemelha ao do hambúrguer vegano.

Tabela 3 - Resultado das análises microbiológicas dos hambúrgueres.

\begin{tabular}{lccc}
\hline \multirow{2}{*}{ Análises } & \multicolumn{2}{c}{ Formulações } & Padrões \\
\cline { 2 - 3 } & HV01 (UFC. g-1) & HV02 (UFC. g-1) & microbiológicos \\
\hline Bolores e Leveduras/g & $2,2 \times 10^{2}$ & $1,3 \times 10^{2}$ & $*$ \\
Coliformes a $45^{\circ} \mathrm{C} / \mathrm{g}$ & Ausência & Ausência & $10^{2 * *}$ \\
Salmonella $\mathrm{sp} / 25 \mathrm{~g}$ & Ausência & Ausência & Ausência em \\
& & & $25 \mathrm{~g} * *$ \\
\hline
\end{tabular}

Fonte: *: Determinação não preconizada Instrução Normativa n 60 (BRASIL, 2019); ** (BRASIL, 2019). HV01 - jaca in natura; HV02 jaca tratada termicamente.

Para os parâmetros microbiológicos de Bolores e Leveduras/g foram encontrados valores para HV01 (2,2x10²) e HV02 $\left(1,3 \times 10^{2}\right)$, os padrões não são preconizadas para pela Instrução Normativa $\mathrm{n}^{\circ} 60$ para este produto, sendo assim, para posterior discussão de resultados essa especificação será comparada com experimentos semelhantes a esse estudo. Certificou-se ausência 
para Coliformes a $45^{\circ} \mathrm{C} / \mathrm{g}$ e ausência para Salmonella sp $/ 25 \mathrm{~g}$, as mesmas foram realizadas nas matérias-primas vegetais do HV01 e HV02 antes do preparo para consumo. A fim de comparar esses achados utilizou-se padrões microbiológicos que mais se assemelham ao produto que foi de processado para frutas, produtos de frutas e similares branqueadas ou cozidas, inteiras ou picadas, estáveis a temperatura ambiente, refrigeradas ou congeladas preconizada pela Instrução Normativa $n^{\circ} 60$, de 23 de dezembro de 2019; n 2; item "c" (Brasil, 2019).

\subsection{Caracterização da análise sensorial}

De acordo com a Figura 3, pode-se observar as médias de aceitação para os atributos aparência, cor, aroma, sabor, textura e avaliação global. Os resultados encontrados para aparência no HV01 $(8,0)$ e HV02 $(7,0)$ manifestaram uma diferença maior do que seria esperado eventualmente, sendo assim existe uma distinção significativa ( $\mathrm{P}<0,01)$, sendo a amostra preparada com a jaca dura in natura a mais aceita pelos participantes da análise no tocante à essa característica. Em relação aos outros parâmetros, a cor do hambúrguer, com média para o HV01 (7,0) e HV02 (6,0), foi o atributo que exibiu a menor diferença estatística, ainda sim a mesma foi significante $(\mathrm{P}<0,05)$, sendo a amostra HV01 a formulação mais aprovada nesse quesito.

Figura 3 - Médias de aceitação em escala hedônica das duas formulações de hambúrguer vegano.

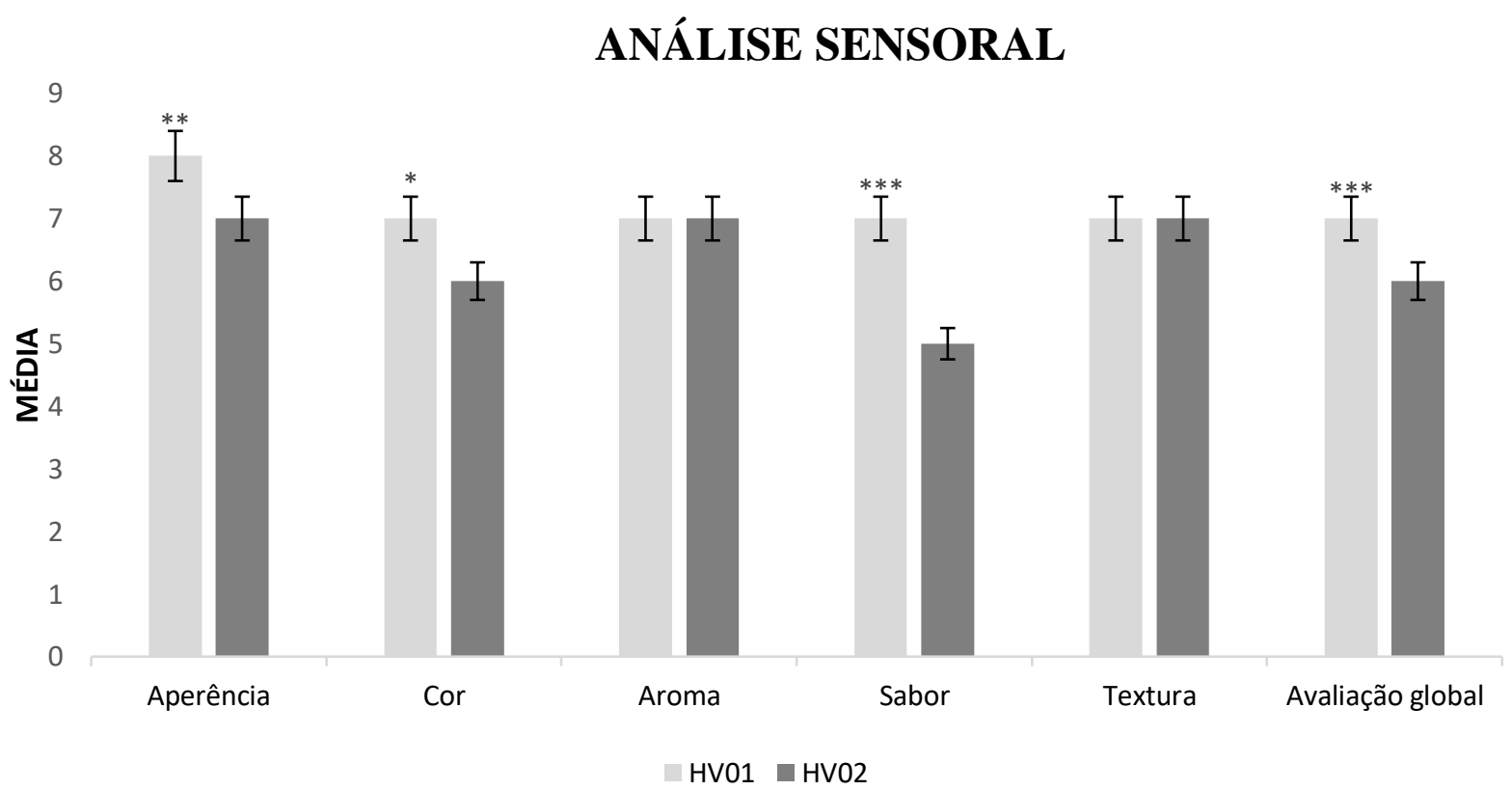

Interpretação de escala hedônica em avaliação sensorial de HV01 - jaca in natura (n 60); HV02 - jaca tratada termicamente (n 60). Os dados foram analisados utilizando médias comparadas pelo teste $\mathrm{t}$ de Tukey e o teste de $\mathrm{t}$ Student ao nível de $5 \%$ de significância. * $\mathrm{P}<0.05$, **P $<$ $0.01, * * * \mathrm{P}<0.001$. Fonte: Autores.

Simultaneamente, os atributos que manifestaram diferenças mais significativas da análise sensorial em questão são os de sabor e avaliação global, ambas amostras obtiveram média de aceitação "7 - gostei moderadamente". Em relação a diferença entre os valores médios dos dois grupos, a mesma é maior do que seria esperada casualmente, logo, existe uma diferença estatisticamente significante $(\mathrm{P}<0,001)$ mostrando assim maior aceitabilidade, em relação a esses dois atributos, para a formulação HV01.

Para os parâmetros aroma e textura os valores das médias se expressaram iguais para as duas amostras (7,0). Em relação às diferenças estatísticas, a distinção dos valores médios entre as duas formulações de hambúrguer vegano não foram amplas o bastante para demostrar significância expressiva. Assim, não existiu uma amostra mais aceita em relação aos dois aspectos em questão. 
De acordo com a Figura 4, (ver Figura 4), pode-se observar as médias de intenção de compra para as amostras e os resultados foram expressos em cinco pontos onde 5 equivale a "compraria" e 1 "jamais compraria". Os resultados mostram que o hambúrguer HV01 obteve média (4,0) e o HV02 (3,0), ou seja, os provadores "possivelmente comprariam" e "talvez comprassem/talvez não comprassem" as amostras, respectivamente. Embora próximos, a diferença dos valores encontrados para a média é maior do que se esperava ocasionalmente, de modo que existiu uma diferença bastante significante $(\mathrm{P}>0,01)$ quando comparada como nível estipulado. Assim a amostra HV01 seria a mais adquirida no mercado pelos consumidores que participaram da análise sensorial.

Figura 4 - Médias de intenção de compra em escala hedônica das duas formulações de hambúrguer vegano.

\section{INTENÇÃO DE COMPRA}

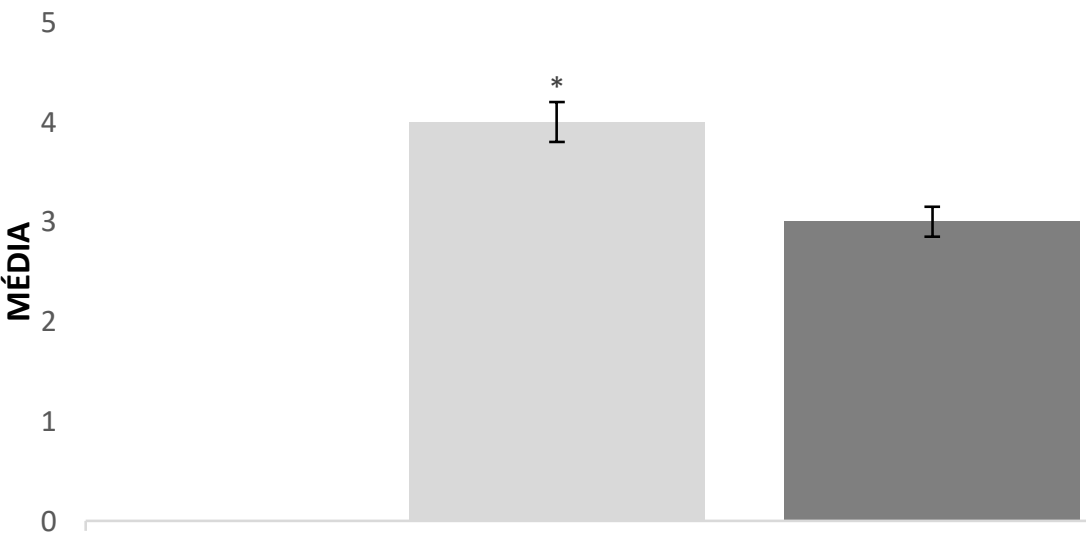

HV1 HV2

Interpretação de escala hedônica para intenção de compra do HV01 - jaca in natura (n 60); HV02 - jaca tratada termicamente (n 60). Os dados foram analisados utilizando médias comparadas pelo teste t de Tukey e o teste de t Student ao nível de 5\% de significância. *P < 0.01. Fonte: Autores.

\subsection{Caracterização do rendimento}

Pode-se observar que a formulação HV01 formulada com a jaca dura crua apresentou o menor rendimento (83,6\%), já a formulação elaborada a partir da base vegetal tratada termicamente (HV02) mostrou maior rendimento do produto (84,2\%), uma vez que a primeira amostra foi processada com a fruta "in natura” consequentemente terá mais água livre e/ou combinada quando comparação com a segunda amostra, assim, o processo térmico de cocção para consumo pode ter influenciado na menor perda de água do segundo hambúrguer, explicando assim a maior porcentagem de aproveitamento após o preparo para consumo. O mesmo pode ser confirmado com a maior redução do diâmetro da amostra HV01 (4,7\%), visto que, a quantidade de água presente nessa formulação, a partir da jaca dura crua, é maior em relação a outra, como já relatado anteriormente, assim a temperatura exposta na cocção pode ter contribuído para maior perda de água durante o preparo para consumo, tendo potencial para redução do tamanho da amostra. Todos esses dados podem ser observados na Tabela 4.

Tabela 4 - Característica de rendimento: análises de redução de diâmetro e rendimento dos hambúrgueres.

\begin{tabular}{lcc}
\hline \multicolumn{1}{c}{ Análises } & \multicolumn{2}{c}{ Formulações } \\
\cline { 2 - 3 } & HV01 & HV02 \\
\hline Rendimento (\%) & $83,6 \%$ & $84,2 \%$ \\
Redução do diâmetro (\%) & $4,7 \%$ & $1,9 \%$ \\
\hline
\end{tabular}

Interpretação das características de rendimento através da média em triplicata do HV01 - jaca in natura; HV02 - jaca tratada termicamente. Fonte: Autores. 


\section{Discussão}

\subsection{Características físico-químicas}

Com relação aos resultados das análises físico-químicas, pode-se dizer que as amostras mostraram baixa umidade quando comparadas com o experimento feito por Lemos (2012), que ao estudar as propriedade físico-químicas da polpa de jaca dura verde encontrou 77,4\% de umidade, teor maior que os apresentados nas amostras HV01 (57,23) e HV02 (54,28\%). Em outro estudo, Morais et al. (2016) apresentaram valores encontrados para a composição centesimal da polpa jaca tratada hidrotermicamente $(67,75 \%)$ mostrando-se também acima do valor encontrado no hambúrguer vegano desta pesquisa. A redução na umidade no produto final da pesquisa em questão se deu pela mistura de vários ingredientes em sua formulação, incluindo as farinhas, fécula de mandioca e condimentos utilizados em forma de pó, transformando-o em um alimento menos úmido com características próximas de um produto processado.

Já em pesquisa realizada por Lima (2008) onde analisou-se um hambúrguer vegetal elaborado à base de caju constatando sua umidade $(49,47 \%)$ resultado abaixo do encontrado no hambúrguer com base vegetal de jaca dura, corroborando assim que cada fruta tem sua umidade especifica e que a maioria apresenta valores para umidade altos, o que reforça a necessidade de conservação sob congelamento. A distinção dos achados desta pesquisa quando comparados com os resultados dos estudos supracitadas se explica pela influência das variáveis na matéria prima como tamanho, estágio de maturação, método de cultivo, época de colheita, clima e vários outros pontos que possam refletir na qualidade final do fruto.

Sobre a atividade de água não foram observadas diferenças significativas nas amostras analisadas. Os valores observados do HV01 $(0,991)$ e do HV02 $(0,978)$ são elevados e apresentam-se semelhantes aos encontrados pelo mesmo estudo acima citado $(0,961)$, no qual Lima (2008) explica que no entanto, como os hambúrgueres são armazenados congelados e retirados da refrigeração apenas na etapa de preparação e consumo, os valores elevados para Aw não manifestam problemas para sua conservação, levando também em consideração os insumos adicionados na estabilidade e/ou diminuição de possíveis atividades microbianas. Os valores encontrados nesta pesquisa, além de serem semelhantes aos encontrados na referência acima mencionada, ainda seguem análogos em outros experimentos com produtos similares ao desta pesquisa, como por exemplo o de Lima (2018) que produziu um hambúrguer vegano de grão-de-bico com resíduo agroindustrial de acerola, achando valores de atividade de água nas amostras cruas bastante elevados, com valores entre 0,949 e 0,979.

Para os resíduos inorgânicos presentes nas amostras, ou seja, o teor de cinzas manteve-se entre HV01 (2,56\%) e HV02 $(2,58 \%)$. Pode-se observar assim, que ambas apresentaram conteúdo mineral semelhantes e a diferença entre o processamento não influenciou diretamente nesse parâmentro. Levando em consideração que o teor de cinzas da polpa da jaca "in natura" que foi de (1,03\%), constatado em um estudo realizado por Da Silva et al. (2018), juntamente com a porcentagem da cinzas da farinha da semente que foi de (1,53\%) observado em outro experimento feito por Santos (2009). Constata-se assim, que a combinação de ambos e dos demais insumos utilizados na preparação do produto contribuiu com que os resultados tendessem às porcentagens achadas nas duas amostras.

Quando observa-se os valores para acidez titulável, percebe-se que as amostras mostram valores reduzidos HV01 $(0,48 \%)$ e HV02 (0,45\%), sendo assim é grande a possibilidade de que o tratamento térmico de uma da amostra não tenha influenciado nesse quesito, porém os baixos valores encontrados se explicam pela utilização do fruto verde, ou seja, imaturo, pois seria apenas na fruta madura que compostos como ácidos fenólicos e algumas vitaminas estariam em quantidades maiores, influenciando assim nesse parâmetro no produto final. Quando comparado com outros estudos, o experimento ainda obteve maior acidez em relação ao achado de Leme (2012), que observou (0,30\%) em hambúrguer feito com fibra de caju, intitulado cajáburguer.

Quanto ao teor de lipídeos, pode-se perceber que ambas amostras demonstraram reduzida quantidade de gordura, porém hambúrguer HV01 (2,15\%) foi certificado valor relativamente superior a amostra HV02 (1,00), desta maneira, a variável 
temperatura pode ter influenciado nessa diferença numérida, uma vez que não foi adicionado em quaisquer etapa do processamento nenhum ingrediente com quantidade de gordura que viesse a influenciar na elevação desses valores, dando assim ao produto uma característica hipolipídica.

Segundo a Portaria 234 (Brasil, 1996), o Ministério da Saúde estabelece que alimentos sólidos com teor de lipídeos inferior a 3\% são apontados como de "baixo teor de gordura" e quando o produto apresenta redução mínima de 25\% em gordura, comparado ao produto convencional, é considerado como de "teor reduzido de gordura". Neste caso, as duas formulações podem ser enquadradas como "baixo teor de gordura", pois seus valores foram bem menores do que 3\%.

O valor observado na amostra HV02 é semelhante a observada por Lima (2013) quando analisou um hambúrguer vegetal de fibra de caju e proteína texturizada de soja. Se comparada com outros experimentos de análises físico-químicas, esse valor de lipídeos se mostrou bem diminuída. Porém, vale salientar que nessas pesquisas adicionaram-se insumos que resultaram em tal feito, por exemplo, no estudo feito por Leme (2012) pode-se verificar cerca de $(8,28 \%)$ no hambúrguer, uma vez que para sua formulação foram utilizados ingredientes que elevaram o valor inicial, como a adição de óleo de soja.

\subsection{Características microbiológicas}

Quando a presença de Bolores e Leveduras os resultados mostram amostras positivas, apresentando para a amostra HV01 (2,2 x 10² UFC/g) e (1,3 x 10² UFC/g) para a amostra HV02. Convém destacar que a legislação brasileira não determina limites para esse parâmetro em hambúrgueres processados com frutas e afins. Segundo Torrezan, Eiroa e Pfenning (2000) os maiores números de microrganismos contaminantes dos frutos habitam na sua fração externa, sendo a sua parte interior de fato estéril, a menos em que alguma etapa da sua produção cause algum choque mecânico que comprometa a estrutura íntegra de sua casca.

Sendo assim, como a jaca dura é um fruto de grande porte, seu processamento foi fatigante necessitando da utilização de muitos utensílios, explicando assim a presença de atividade microbiana, todavia, a análise foi realizada com o produto antes de seu preparo para consumo, e, submetendo-o ao processo de cocção limitou-se ainda mais os microrganismos ali presentes, sendo que as altas temperaturas tem efeitos lesivos sobre a microbiota, por essa razão esse artifício é usado na conservação de alimentos ( Franco \& Landgraf, 2005, Leme, 2012).

Não estando disponível no mercado, ainda não existem padrões microbiológicos para confrontação dos resultados. No entanto, os resultados aferidos representam um produto com características microbiológicas aceitáveis para o consumo, dado valor $>101 \mathrm{UFCG} / \mathrm{g}$ de Coliformes a $45^{\circ} \mathrm{C} / \mathrm{g}$ o que indica um processamento com boas condições higiênico-sanitárias adequadas, ainda que fossem elaborados com matéria-prima animal, para hambúrgueres de carne bovina seriam obrigatórios valores inferiores a $5 \times 10^{3}$ de acordo com Instrução Normativa vigente. Nas duas amostras foi observado resultados satisfatórios para Salmonella sp/25g, isto significa que, não foi constatado a existência desse microrganismo nos hambúrgueres. A presença de salmonela em alimentos é proibida pela Instrução Normativa n 60, de 23 de dezembro de 2019; n 2; item “c” (Brasil, 2019).

Quando comparados com Lima et al. (2011) os achados verificados foram satisfatórios, os autores encontraram < 3 NPM/g para Coliformes e ausência de Salmonella sp., em um estudo que visou observar a estabilidade durante armazenamento de hambúrguer vegetal elaborado à base de caju armazenados congelados, a temperatura de $-18{ }^{\circ} \mathrm{C}$, por seis meses. Portanto, para uma maior segurança dos consumidores e a obtenção de qualidade aceitável é de grande relevância um experimento em etapas, semelhante ao estudo acima citado, para constatar um possível prejuízo de sua qualidade físico-química, microbiológica e sensorial. 


\subsection{Características sensoriais}

O atributo aparência para a amostra HV01 foi o quesito que demonstrou a maior média em comparação a todos os outros analisados no experimento sensorial. Quando comparado com HV02 a diferença pode ser explicada através da modificação visual que o tratamento térmico provocou na base vegetal durante o processamento prévio, esse fator pode ter sido acentuado ainda mais após o preparo para consumo, visto que o hambúrguer passou por mais um processo térmico, além do mais, a diferença entre a umidade, mesmo que não relevante, pode ser outro fator que corroborou para a diferença significativa entre a aceitação dessa medida. Esse resultado é melhor quando comparado com um experimento de formulação do tipo hambúrguer vegetal realizado por Galvão (2006) que aproveitando da fibra de caju, obtendo média $(7,5)$ na formulação com maior teor de fibras, sendo semelhante ao achado por Leme (2012) na avaliação de um hambúrguer, onde sua carne básica foi elaborada com $84 \%$ com fibra de cajá e insumos vegetais, apresentando média $(7,1)$. Sendo assim o hambúrguer elaborado com jaca dura mostrou melhor aparência quando comparados com outros produtos semelhantes.

Apresentando resultado com significância precisa $(\mathrm{p}<0,05)$ a característica cor foi a que mais despertou comentários dos participantes, eles relataram desgostar bastante da amostra HV02, visto que, essa apresentou-se bem mais escura em relação a outra, assim sendo, mais uma vez, a dupla exposição a temperatura elevadas, no processamento e no preparo, foi o fator responsável. Segundo Fiorenza e Fantin (2015) a cor do produto exibe uma primeira reprodução e influência na opinião do consumidor, que reflete de modo direto no seu desejo de consumir ou recusar o produto, propicia também uma designação sobre o grau de qualidade e conservação. É importante salientar que os insumos adicionados na formulação de ambas amostras não possuíam nenhuma coloração forte que pudesse influenciar no resultado desse item.

As amostras HV01 e HV02 obtiveram médias iguais tanto para a variável aroma quanto para textura e também não apresentaram diferenças significativas entre amostras ( $\mathrm{p}>0,05)$, o que indica que nenhuma etapa do processamento, tratamento térmico prévio, para consumo e adição de insumos, influiu na diferenciação das amostras e não influenciou diferenças entre aceitação dos produtos pelos provadores, com relação a esses atributos. Contudo, essas medidas se mostram semelhantes as achadas por Moro (2019) que obteve médias entre 6 e 7 no hambúrguer vegano de grão de bico com adição de ora-pro-nóbis, sendo resultados considerados positivos. Sobre as médias de aceitação, podemos constatar que entre 6 e 9 , em escala hedônica de 9 pontos, são consideráveis bons preditores de aceitação sensorial no mercado. Então, mostra-se assim, que o hambúrguer de jaca dura conseguiu mais um resultado positivo nesse experimento Muños, Civille e Car (1992).

Por fim, as duas características que mais apresentaram diferenças significativas entre amostras foram a de sabor e avaliação global ( $\mathrm{p}<0,001)$ para a HV01, as duas também apresentaram mesma média, mostrando que os provadores gostaram moderadamente, colaborando assim para conclusão de que as etapas do processamento tiveram influências positivas no resultado final do produto. Citando as observações feitas pelos provadores, a amostra em questão apresentou-se mais semelhante ao hambúrguer elaborado com matéria prima animal existentes no mercado. Outro fator de relevância é que durante as etapas de mistura de insumos e modelagem, os ingredientes expressaram mais aglutinação, atenuando sabor mais especifico ao produto. Os resultados são semelhantes aos encontrados por De Oliveira Rosa e Lobato (2020) em análise sensorial de hambúrguer a base de fibra de caju.

Além da análise sensorial com escala hedônica de 9 pontos, interrogou-se aos consumidores do experimento a respeito da intenção de compra para as duas formulações, os resultados encontrados mostram que a maioria "4 - possivelmente compraria" a formulação HV01, resultado esperando, levando em consideração os achados da análise dos atributos acima citados. Esses resultados foram semelhantes para a maioria das amostras em um estudo desenvolvido por Farias (2016) utilizando diferentes tipos de hambúrgueres funcionais utilizando o reaproveitamento de alimentos exclusivamente vegetais. Portanto, a amostra seria a melhor opção para consumidores de hambúrguer vegano. 


\subsection{Características do rendimento}

Com relação aos parâmetros do processamento térmico dos hambúrgueres os resultados que foram analisados identificaram a amostra HV01 como a de menor rendimento, esse achado tem relação direta com a forma que a mesma foi processada, "in natura", não passando por nenhum processo que pudesse influenciar a perda de agua. Essa afirmação pode ser claramente observada no resultado da análise físico-química para essa amostra, que comprovou diferença entre a porcentagem de umidade, embora não significante, do que na amostra HV02, esta, por ter sofrido ação de temperatura por um período de uma hora a $220^{\circ} \mathrm{C}$, resultou em perda de umidade, e então, no preparo para consumo a amostra em questão não apresentou novas perdas relevantes. É importante relatar que a atividade de água em ambas amostras não tiveram diferenças significativas, porém, ainda observou-se uma mínima diferença entre amostras, o que certifica ainda mais a notável explicação do maior rendimento na amostra HV02.

Todas as hipóteses acimas citadas se relacionam com a diferença de umidade, embora que não significante, e exposição de temperatura que diferiram entre as duas amostras. Deste modo, o diâmetro dos hambúrgueres também sofreu interferência por essas variáveis, a amostra HV01 obteve maior redução do diâmetro, então, sua forma de processamento influenciou diretamente em maiores perdas no tamanho do hambúrguer em relação a amostra HV02, essa então mostrou que o processo térmico prévio influenciou diretamente na menor redução do diâmetro após o preparo para o consumo final.

Embora algumas diferenças observadas entre as amostras, vale salientar que os resultados foram muito expressivos quando comparados com estudos semelhantes, é o que comprova Seabra (2002), que em um estudo utilizando fécula de mandioca e farinha de aveia na formulação de hambúrguer de carne ovina, constatou que a amostra que possuía apenas a fécula apresentou maior rendimento $(72,77)$ e a menor redução de diâmetro $(15,47)$ entre todas amostras. Do mesmo modo, Braga $(2008)$ em um experimento adicionando amido de mandioca e farinha de aveia na formulação de hambúrguer de polpa de tilápia-do-nilo, observou que a única amostra que apresentou aumento do rendimento $(83,65)$ e redução o encolhimento $(13,15)$ foi a que utilizou a amido de mandioca adicionado à formulação do hambúrguer.

Os estudos acima relatados utilizam matéria prima animal e constaram que a utilização da fécula de mandioca colabora de forma positiva nos parâmetros em questão, como o hambúrguer vegano foi elaborado apenas com base vegetal, a quantidade de amido é maior, o que colabora assim para a maior rentabilidade e menor redução do diâmetro no momento do preparo.

\section{Considerações Finais}

A escolha do experimento se deu devido à percepção no possível mercado consumidor de uma população em constante crescimento, os veganos. Esse perfil de consumidor em ascensão impulsiona a indústria de alimentos na intensificação da busca por produtos cada vez mais arrojados que utilizem uma matéria prima subutilizada e que seja de origem local, despertando assim ainda mais o entusiasmo desse público no ato da busca por gêneros desse perfil, uma vez que, a variabilidade de itens do tipo "hambúrguer vegano” não seja muito expressiva nos supermercados comuns e nos especializados nessas mercadorias.

A metodologia empregada buscou elaborar um alimento $100 \%$ processado com itens vegetais, em relação aos condimentos e a base utilizada, atribuindo assim ao produto, peculiaridade hipolipídica, hipocalórica e hipossódica, deste modo será concedido ao produto uma imagem distante dos alimentos processados, como os hambúrgueres elaborados com matériaprima animal. A realização das análises de todas as características que o experimento possibilitou, a fim de provar a capacidade do produto em representar resultados positivos, foi de importante relevância, visto que, a tecnologia de alimentos abrange inúmeros métodos investigativos para determinar tal feito.

Ao realizar experimentos analíticos em hambúrguer artesanal do tipo vegano utilizando a polpa, mesocarpo e semente de jaca, ainda com a adição de farinha de couve folha, identifica-se que ambas amostras do produto apresentam ótimas qualidades microbiológicas e físico-químicas. Sendo assim, é um alimento seguro e benéfico para os consumidores que buscam esse 
consumo por determinados fins, seja pela conservação da vida animal ou por buscarem a prevenção e/ou reabilitação de agravos provocados, por exemplo, por um perfil alimentar que consuma hambúrgueres bovinos ricos em gordura saturada, colesterol e sal.

Além disso, observando os achados da análise sensorial, deduz-se que com o processamento do produto utilizando a fruta in natura (HV01) obteve-se mais aceitação pelos participantes provadores das formulações, de acordo com os mesmos existe a considerável probabilidade de compra e consumo. Convém destacar que esta amostra conseguiu alcançar maiores diferenças significativas entre parâmetros sensoriais, embora tenha passado por quase todas as mesmas etapas de tratamento que a outra opção de hambúrguer.

Entende-se ainda que a amostra mais evidenciada em resultados positivos ainda se mostrou como a melhor opção em termos de rendimento para a indústria alimentícia, sendo a escolha mais preferível para um custo-benefício mais aproveitável em termos de gastos financeiros e uso de matéria prima.

Constata-se por fim, que os objetivos da pesquisa foram alcançados, porém pesquisas mais detalhadas podem ser realizadas, como análise da vida de prateleira, métodos quantitativos de carboidratos e proteínas, métodos investigativos da presença de compostos fenólicos e moléculas bioativas. Novas idealizações utilizando a jaca dura podem ser criadas usando a mesma de forma integral, uma vez que nesse estudo a sua casca e seu eixo foram descartados, podendo serem testados seja na formulação do produto em questão, ou para outros fins. Portanto, é sempre considerável pensar em novos produtos que aproveitem matérias vegetais subutilizadas, tento em vista que a árvore da jaca produz frutos abundantes em tamanho e quantidade, muitas vezes chegando ao seu estado máximo de maturação e por fim, à sua decomposição, sem que se possa aproveitar suas outras potencialidades, além do consumo in natura ou na forma de doces.

\section{Referências}

Association of Official Analytical Chemists- AOAC. (1995). Official methods of analysis of the Association of Official Analytical Chemists. (16a ed.), Washington: AOAC, 2v.

Braga, G. C., Pasquetti, T. J., Bueno, G. W., \& Merengoni, N. G. (2008). Adição de amido e farinha de aveia na formulação de hambúrguer de polpa de tilápiado-nilo (Oreochromis niloticus). Scientia Agraria Paranaensis, 45-54. https://doi.org/10.18188/sap.v0i0.2051

Brasil. (1996). Ministério da Saúde, Portaria no 234 de 21 de maio de 1996. Normas técnicas referentes a alimentos para fins especiais. Diário Oficial da União, Brasília, n.101, p.9135, seção 1. http://bvsms.saude.gov.br/bvs/saudelegis/svs1/1996/prt234_21_05_1996_rep.html

Brasil. (2019). Agência Nacional de Vigilância Sanitária. Ministério da Saúde. Instrução Normativa n 60, de 23 de Dezembro de 2019 . Diário Oficial da União $\mathrm{n}^{\circ}$ 249, de 26 de dezembro de 2019. http://www.cvs.saude.sp.gov.br/zip/U_IN-MS-ANVISA-60_231219.pdf.

Da Silva, L. P. F. R.; Vieira, A. F.; Costa, Z. R. T.; Rodrigues, L. M. D. S. \& Queiroz, A. J. D. M. (2018). Caracterização físico-química da polpa de jaca (Artocarpus heterophyllus). In CONTECC Congresso Técnico Científico da Engenharia e da Agronomia. Maceió-AL, Brasil. https://www.confea.org.br/sites/default/files/antigos/contecc2018/agronomia/54_cfqdpdj.pdf

Farias, P. K. S., Souza, S. D. O., de Oliveira Santana, I. M., Prates, R. P., Gusmão, A. C. M., \& de Freitas Soares, P. D. (2016). Desenvolvimento e análise sensorial de diferentes tipos de hambúrgueres funcionais utilizando o reaproveitamento de alimentos. Caderno de Ciências Agrárias, 8(3), 07-14. https://periodicos.ufmg.br/index.php/ccaufmg/article/view/2937.

Fiorenza, A. B., \& Fantin, B. (2015). Influência da adição de farelo de aveia nas propriedades físicas de hambúrguer de frango (Bachelor's thesis, Universidade Tecnológica Federal do Paraná). http://repositorio.roca.utfpr.edu.br/jspui/handle/1/8071.

Folch, J., Lees, M., \& Stanley, G. S. (1957). A simple method for the isolation and purification of total lipides from animal tissues. Journal of biological chemistry, 226(1), 497-509. https://www.jbc.org/content/226/1/497.short\#ref-list-1

Franco, B. D. G. M., \& Landgraf, M. (2005). Micobiologia dos alimentos. Atheneu, 182 p.

Galvão, A. M. P. (2006). Aproveitamento da fibra de caju (Anacardium occidentale 1.) na formulação de um produto tipo hambúrguer. http://www.repositorio.ufc.br/handle/riufc/17220.

Karlsen, M. C., Rogers, G., Miki, A., Lichtenstein, A. H., Folta, S. C., Economos, C. D., \& McKeown, N. M. (2019). Theoretical food and nutrient composition of whole-food plant-based and vegan diets compared to current dietary recommendations. Nutrients, 11(3), 625. https://doi.org/10.3390/nu11030625.

Landim, L. B., Bonomo, R. C. F., Reis, R. C., da Silva, N. M. C., Veloso, C. M., \& Fontan, R. D. C. I. (2012). Formulação de Quibes Com Farinha de Semente de Jaca. Journal of Health Sciences, 14(2). https://doi.org/10.17921/2447-8938.2012v14n2p\%25p. 
Leme, A. V. P. (2012). Cajúburguer: avaliação físico-química, microbiológica e sensorial (Doctoral dissertation). http://hdl.handle.net/123456789/89.

Lima, É. C. D. (2018). Produção de hambúrguer vegano de grão-de-bico com resíduo agroindustrial de acerola (Bachelor's thesis, Universidade Federal do Rio Grande do Norte). http://monografias.ufrn.br/handle/123456789/7910.

Lima, J. R. (2008). Caracterização físico-química e sensorial de hambúrguer vegetal elaborado à base de caju. Ciência e Agrotecnologia, 32 (1), 191-195. https://doi.org/10.1590/S1413-70542008000100028.

Lima, J.; Modesto, A.; Firmino, D.; Pinto, G.; de Lima, L. V.; de Oliveira, L. M. V., \& Paula Pessoa, P. F. A. (2013). Hambúrguer vegetal de fibra de caju e proteína texturizada de soja: obtenção e avaliação de viabilidade econômica da produção. Embrapa Agroindústria Tropical-Comunicado Técnico (INFOTECAE). https://www.infoteca.cnptia.embrapa.br/bitstream/doc/981708/1/COT13008.pdf.

Lima, J. R., Bruno, L. M., \& de Souza Neto, M. A. (2011). Estabilidade durante armazenamento de hambúrguer vegetal elaborado à base de caju. Embrapa Agroindústria Tropical-Boletim de Pesquisa e Desenvolvimento (INFOTECA-E). https://www.infoteca.cnptia.embrapa.br/bits tream/doc/905012/1/BPD11003.pdf.

Mansour, E. H., \& Khalil, A. H. (1997). Characteristics of low-fat beefburger as influenced by various types of wheat fibers. Food Research International, 30(34), 199-205. https://doi.org/10.1016/S0963-9969(97)00043-4

Morais, D. N. et al. (2016). Desenvolvimento de Hambúrguer 100 \% Vegetal a Base de Polpa e Farinha da Semente de Jaca (Artocarpus heterophyllus L.). VI International Technical Symposium: Alimentação: a árvore que sustenta a vida, Anais FAURGS- Gramado/RS. http://www.ufrgs.br/sbctarseventos/xxvcbcta/anais/files/450.pdf

Moro, G. L. (2019). Desenvolvimento e caracterização de hambúrguer vegano de grão de bico (Cicer arietinum L.) com adição de ora-pro-nóbis (Pereskia Aculeata Mill.). http://repositorio.ufgd.edu.br/jspui/handle/prefix/2559.

Munoz, A. M., Civille, G. V., \& Carr, B. T. (1992). Sensory Evaluation in Quality Control Van Nostrand Reinhold. 320 p.

Paula, G. T., de Farias, H. P. S., Ali, L. R. F. Y., Ribeiro, R. C., da Silva Pereira, V., de Souza Paiva, E., \& Pereira, M. C. P. C. (2019). Desenvolvimento de uma formulação do "tipo hambúrguer" de okara com shitake. Semioses, 13(1), 33-46. https://doi.org/10.15202/1981996x.2019v13n1p33.

Pedro, N. (2010). Dieta vegetariana: fatos e contradições. Medicina Interna, 17(3), 173-8. https://www.spmi.pt/revista/vol17/vol17_n3_2010_173_178.pdf.

Pereira, A. S. et al. (2018). Metodologia da pesquisa científica. AB/NTE/UFSM. https://repositorio.ufsm.br/bitstream/handle/1/15824/Lic_Computacao_M etodologia-Pesquisa-Cientifica.pdf?sequence $=1$

De Oliveira Rosa, M. Y., \& Lobato, F. H. S. (2020). Cashew burger: elaboração e análise sensorial de hambúrguer à base de caju (anacardium occidentale 1). Research, Society and Development, 9(8), e615985958-e615985958. https://doi.org/10.33448/rsd-v9i8.5958.

Santos, C. T. (2009). Farinha da semente de jaca: caracterização físico-química e propriedades funcionais. Itapetinga-BA: UESB, 73p (Dissertação de Mestrado em Engenharia de Alimentos-Universidade Estadual do Sudoeste da Bahia). http://www2.uesb.br/ppg/ppgecal/wp-content/uploads/2017/04/CALILASANTOS.pdf.

Seabra, L. M. A. J., Zapata, J. F. F., Nogueira, C. M., Dantas, M. A., \& Almeida, R. B. D. (2002). Fécula de mandioca e farinha de aveia como substitutos de gordura na formulação de hambúrguer de carne ovina. Food Science and Technology, 22(3), 245-248. https://doi.org/10.1590/S0101-20612002000300008.

Torrezan, R., Eiroa, M. N. U., \& Pfenning, L. (2000). Identificação de microrganismos isolados em frutas, polpas e ambiente industrial. Boletim do Centro de Pesquisa de Processamento de Alimentos, 18(1). https://revistas.ufpr.br/alimentos/article/viewFile/1122/923.

Trigueiro, A. (2013). Consumo, ética e natureza: o veganismo e as interfaces de uma política de vida. Revista Internacional Interdisciplinar INTERthesis, 10(1), 237-260. https://doi.org/10.5007/1807-1384.2013v10n1p237. 